Article

\title{
Why Do People Return to Video Platforms? Millennials and Centennials on TikTok
}

\author{
Pedro Cuesta-Valiño ${ }^{1, *}$, Pablo Gutiérrez-Rodríguez ${ }^{2}$, and Patricia Durán-Álamo ${ }^{1}$ \\ ${ }^{1}$ Department of Economics and Business Management, Universidad de Alcalá, Spain \\ 2 Department of Business Administration, Universidad de León, Spain \\ * Corresponding author (pedro.cuesta@uah.es)
}

Submitted: 26 July 2021 | Accepted: 6 September 2021 | Published: 24 February 2022

\begin{abstract}
While some social networks like Facebook are losing interest among digital influencers, TikTok continues to grow, capturing and impacting centennials and millennials alike. This situation highlights the new generations' increasing interest in short video formats, which are also becoming a new window of communication between companies and consumers. TikTok allows users to create, share, and discover short, user-generated videos in hopes of attracting viewers. But it is necessary to understand the variables that attract and engage users of these particular social networks. This article analyses the variables of continuance motivation, video sharing behaviour, and video creation capabilities, which allow users to enjoy such networks, and service providers and companies to obtain results from them. The aim is to understand how these variables motivate social media users to return to and spend more time on this video-sharing platform. This is measured through the stickiness variable. In this context-and due to the particular relevance of the topic-the authors also aim to reveal any potential differences in the behaviour of centennials and millennials when using TikTok. Therefore, a cross-sectional study was conducted through a questionnaire answered by 2,301 millennials and centennials who use TikTok. The data were analysed through a structural equation model to measure the relevance of each of the variables to stickiness. The results provide guidelines for improving research on video social media platforms, as well as an opportunity to explore the importance of the selected variables to the stickiness variable across different user segments.
\end{abstract}

\section{Keywords}

centennials; continuance motivation; millennials; social networks; stickiness; TikTok; video creation; video sharing behaviour

\section{Issue}

This article is part of the issue "New Narratives for New Consumers: Influencers and the Millennial and Centennial Generations" edited by Luis M. Romero-Rodríguez (Rey Juan Carlos University), Santiago Tejedor (Autonomous University of Barcelona) and Inmaculada Berlanga (International University of La Rioja).

(C) 2022 by the author(s); licensee Cogitatio (Lisbon, Portugal). This article is licensed under a Creative Commons Attribution 4.0 International License (CC BY).

\section{Introduction}

The digital era, in which users are increasingly online, presents challenges and opportunities for both online service providers and companies that want to communicate and sell their products. Social media has transformed the landscape of interaction between people, and between brands and consumers. In this situation, the best-known social networks such as Facebook,
YouTube, WhatsApp, or Instagram have added millions of users worldwide. Faced with these successful formats, TikTok has differentiated itself as a mobile application that serves mainly to create and share short, entertaining videos. The essence of this social network is what is known as user-generated content; in other words, the content on the network is generated by the users themselves. TikTok's success has been immediate, and it became the most downloaded non-game mobile app of 
2020 , also ranking second in consumer spending (Sydow, 2020). This confirms the rapid growth of the industry of short video platforms (Liu et al., 2019).

It is therefore necessary to better understand the variables and strategies that determine a development that ensures billions of people are so in love with social networks that they spend several hours a day posting and commenting on them. This variable is stickiness, and it is of great importance in the study of social networks. Nevertheless, there is another range of different variables that have a direct and indirect influence on social networks' stickiness. This study examines stickiness to TikTok, the international version of China's mobile short video platform (Chen et al., 2019). Different studies have shown the evident impact of variables such as continuance motivation (Hsu et al., 2015; Klobas et al., 2018; Wu et al., 2010), sharing behaviour (Khan, 2017; Törhönen et al., 2020), and perceived video creation ability (Chiang \& Hsiao, 2015) on TikTok's stickiness. This article aims to go beyond existing research to find out whether there is a difference between the behaviour of centennials and millennials on TikTok based on the variables analysed.

\section{Conceptual Framework and Hypothesis}

Many researchers have studied the concept of stickiness in recent years. Zott et al. (2000) define stickiness as the power of a website to retain and attract new customers. This power motivates them to stay on the platform (Marchand, 2000). According to Hsu and Liao (2014, p. 836) "a website is considered sticky when its users spend an above-average amount of time browsing it, when they visit the site frequently." The main means of generating stickiness on a website or social platform are the content (Hu et al., 2020; Lu \& Lee, 2010; Xu et al., 2018) and communication style (Fitriani et al., 2020). Lu and Lee (2010) indicate that if you know your audiences, companies from all sectors can create specific contents which give them the opportunity to increase stickiness. Different researchers have studied the influence of stickiness in many sectors, including Lien et al. (2017) in instant messaging applications such as WeChat, Wang et al. (2016) in e-commerce, and Chiang and Hsiao (2015) in video platforms like YouTube. Others such as Zhang et al. (2017) have studied the term to give companies practical guidance on how to encourage customer engagement and increase the stickiness of company social networks through content. Recently, other researchers have focused on the role of digital influencers in generating follower stickiness (Hu et al., 2020), focusing on parasocial relationships and wishful identification as a key to social network stickiness.

Stickiness on social media platforms and smartphones has also received some attention. Wu et al. (2016) argue that, in the case of smartphones, stickiness is achieved by making whatever is appropriate to influence users' affective state, such as emotions, part of their life. Another way of generating stickiness on social media platforms takes the form of communities and external influences. According to Yen (2016), stickiness to the social media site occurs when an individual's intention to contribute knowledge is highly influenced by their peers. In this sense, Chiang and Hsiao (2015) employ the uses and gratifications theory to research factors that influence the stickiness of YouTube. They also use social cognitive theory to test how YouTube users' continuance motivation and sharing behaviour are influenced by environmental and personal factors. However, while many studies have examined social media platforms and smartphone stickiness from the individual and collective point of view, little research has been done on TikTok stickiness and video behaviour.

Motivation seems to have a more relevant role than emotions, insomuch as motivations can explain a user's satisfaction with social network services regardless of whether the users feel positive or negative emotions (Pappas et al., 2020). From another perspective, Camilleri and Falzon (2020) indicate the importance of ritualized motivations in the use of streaming technologies, and Fitriani et al. (2020) show that the utilitarian motivation (credibility) influences channel engagement. As a consequence, it can be said that motivation is an extension of demand, which will lead to the emergence of behaviour (Bi \& Tang, 2017).

Continuance motivation has a strong relationship with uses and gratifications theory because satisfaction is treated as an important antecedent of continued use of social media (Hsu et al., 2015; Wu et al., 2010). Linking in with this point, Wu et al. (2010) show that gratifications have a significant role in continuance motivation, whereas Park et al. (2021) identify social reward as an important motivational factor. Nevertheless, it is known that there are other constructs such as "presence" that do not have a relationship with continuance motivation (Wu et al., 2010).

On video creation platforms, motivations-such as enjoyment and social interaction-have a positive impact on continued engagement and, furthermore, they are necessary to drive the continuity of the activity (Lee \& Quillian, 2019; Törhönen et al., 2020). Other factors have been shown to have significant influence on continuance motivation too (Chiang \& Hsiao, 2015) but some of these motivations - such as social interactionrepresent a way for customers to show their brand inclinations to other people while they use social channels (Lee \& Quillian, 2019). In the same study, continuance motivation refers to the ongoing internal drive to watch and share videos through TikTok.

There are few studies on the relationship between continuance motivation and stickiness. These aim to identify a positive relationship between motivation and people's preference for a choice of media or content (Konstantinos et al., 2002). In the case of online games, Wu et al. (2010) find that the continuance motivation in this type of amusement enhances the stickiness of entertainment media. Following the same relationship, 
stickiness can be further increased if there is motivation for continuity on platforms that use video such as YouTube (Chiang \& Hsiao, 2015).

Taking into account all of the above, the following hypothesis is proposed:

H1: Continuance motivation has a positive relationship on stickiness.

Another construct that is perceived as a trigger in the use of social platforms is "sharing behaviour." A user who arrives in a social media environment or a virtual community is not just looking for information or knowledge; this user also harnesses the platform to meet other people, develop a sense of belonging and build friendships (Chiu et al., 2006). This triggers a consumers' referral tendency, which reflects their propensity to share information with friends, relatives, and other social groups (Koster et al., 2020). As Lee and Ma (2011) note, social media sharing experience and socializing are the two most salient factors that influence intention to share. The rise in popularity of social video content could be ascribed to "increasing prosumerism, the development of live streaming technologies, and popular social video sharing sites such as YouTube, Twitch, Snapchat and Instagram" (Törhönen et al., 2020, p. 166). And in this process, Vermeulen et al. (2018) show that users enjoy receiving likes and positive comments on their positive emotions.

There is a wealth of research analysing sharing behaviour through social media platforms such Facebook or Instagram and video content platforms such as YouTube, Twitch, or TikTok. Vermeulen et al. (2018) focus on how adolescents use different social media platforms, while Lim et al. (2015) study how users of various online social networks create and share information. Ma and Chan (2014) explore the factors contributing to knowledge-sharing behaviour on Facebook and Twitter, and Lee et al. (2015) examine the motivations that drive users to share photos on Instagram. In the video content industry, Khan (2017) analyses what motivates user participation and consumption on YouTube, while Törhönen et al. (2020) look at why people create content on video platforms.

The relationship between sharing behaviour and stickiness is well known. In recent years, some research has shown a strong connection between both constructs. As Yen (2016, p. 127) says, “members' knowledgesharing intention significantly affects collaborative stickiness intention"; thus, social interactions could help to create stickiness (Xu et al., 2018). Taking account of this correlation, it is considered that enhancing the collaboration between others "will make users stick to the service and further motivate them to use" (Lien et al., 2017, p. 409) the services that the platforms offer.

In this sense, users that maintain a closer relationship and share moments and content with others in an online community will develop the power to absorb large amounts of information, generating more stickiness between them (Hsu \& Liao, 2014). Furthermore, Chiang and Hsiao (2015) reflect in relation to video platforms that sharing behaviours are important antecedents of YouTube's stickiness.

Therefore, the following research hypothesis is proposed:

H2: Sharing behaviour has a positive influence on stickiness.

Different users may be driven by different motivations for sharing content on social platforms. In online networking environments, content creation is referred to as user-generated content, which gives to the users the opportunity to report their opinions, thoughts, and original and artistic content with others online (Boyd \& Ellison, 2008). But, as Weeks et al. (2017) state, not every social media user writes a post on Facebook, republishes stories on Instagram, or generates and shares news videos. In this case-TikTok-video is the principal content created by users, so it is necessary to analyse this construct and its influence on the use of social media platforms.

Video content creation is a dynamic activity that encompasses personal satisfaction and social approval (Balakrishnan \& Griffiths, 2017). So, the influence of perceived video creation ability - which is defined by Chiang and Hsiao (2015, p. 90) as “a person's judgment of his or her ability to create valuable or interesting video," an opinion that is shared by Page et al. (2014) - must be taken into account. In this field, Kwane et al. (2020) indicate that perceived competence influences whether to engage or not to engage, and to disclose or not disclose personal information. Meanwhile, Kim et al. (2017) indicate that if the focus is on social approval, enjoyment and social recognition are important motivators for content creation. Furthermore, negative comments have a huge impact on users' desire to share content. As Lortie and Guitton (2013) point out, for some users the fear of being insulted, cursed at, or receiving any other offensive comment is a reason to abstain from uploading personal videos.

Cao et al. (2021) indicate that content creation is the highest level of engagement. This theory has been studied in relation to YouTube by Balakrishnan and Griffiths (2017) who found that content creation had a considerable effect on addiction. Following this perception, Lortie and Guitton (2013) point out that social involvement may have a possible influence on internet addiction behaviours, while Zhang et al. (2017) show that customer engagement has a direct and positive influence on customer stickiness and indirect influence through customer value creation.

If we focus on the values that have a relationship with perceived value, Yang and Lin (2014) showed that hedonic and social value had a significant impact on stickiness. Yen (2016) identifies that social capital and social identity have an effect on knowledge-sharing intention, 
which subsequently has a positive relation on collective stickiness intention towards social networks. Hsu and Chuan-Chuan Lin (2016) reveal that attitude and satisfaction appear to have significant and positive effects on stickiness. Consequently, we consider that if a user feels a perceived video creation ability, the user is going to develop stickiness to the platform.

Taking into account all of the above, the following hypothesis is proposed:

H3: Perceived video creation has a positive relationship on stickiness.

Figure 1 summarizes the relationships proposed in the model between the different variables.

\section{Method}

A descriptive transversal method was carried out to develop the research through a questionnaire that was answered by people between 16 and 40 years old (centennials and millennials) who used TikTok in Spain. The questionnaire was answered between February and May 2021. A total of 2,301 validated questionnaires were collected.

A focus group was held before starting the survey in order to determine that the items in the questionnaire were relevant, and it was made up of eight people: four regular TikTok users (two millennials and two centennials), two executives of social networks companies, and two university professors who teach management on social media. The final questionnaire was obtained as a result of this qualitative research. This questionnaire, in its first part, includes questions about demographic characteristics and items related to the use of TikTok by respondents. And the second section of the questionnaire examines the four dimensions analysed of the proposed model through a 5-point Likert-type scale from 1 (completely disagree) to 5 (completely agree). These measurement scales, that were adapted from the liter- ature review, help to guarantee the validity of the measurement scales and comprise the following: three items for continuance motivation, three for sharing, three for video creation, and three for stickiness (Chiang \& Hsiao, 2015; see Table 1).

A pretest was developed in January 2021 and was answered by 60 people between 16 to 40 years old (30 centennials and 30 millennials) who used TikTok. The objective of this pretest of the questionnaire consisted in assessing whether people understood the items of the questionnaire, as well as validate that the scales were perfectly constructed. Considering all these aspects, the final questionnaire was launched on the main social networks in February 2021. The discretionary non-probabilistic sampling by quotas method was used in order to obtain a representative sample of the Spanish population of TikTok.

The total number of validated questionnaires received was 2,301. The configuration of the sample was $43 \%$ male and $57 \%$ female. By ages, $62 \%$ were $16-25$ years old and $38 \%$ were $26-40$ years old. By educational level, $9 \%$ had a basic education, 30\% intermediate studies, and $61 \%$ higher education. By TikTok usage frequency, $47 \%$ used it every day, $14 \%$ every $2-3$ days, $16 \%$ every $1-4$ weeks, and $24 \%$ less than once a month. And finally, from the point of view of TikTok usage time on a typical day, 35\% used it between 0-15 minutes, 22\% between $16-30$ minutes, $25 \%$ between $31-60$ minutes, and $18 \%$ for more than one hour (see Table 2 ).

\section{Results}

Partial least squares (PLS) combines the benefits of multiple regression and principal component analysis in a single technique. Its use has been shown to be particularly valid when, from a large number of independent variables, a set of dependent variables is predicted. A number of observable variables represents a variable that is not directly observable and is called a latent variable. To configure these variables, researchers have previously

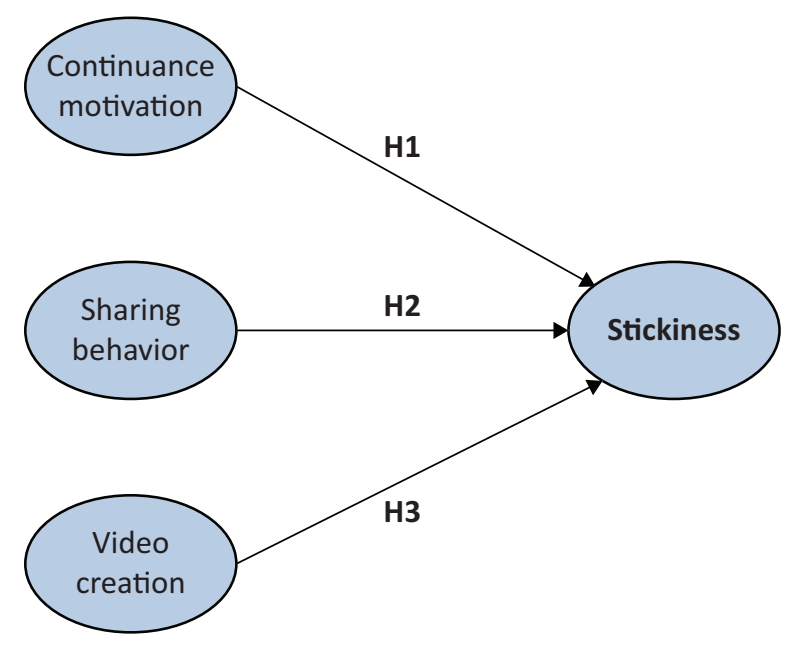

Figure 1. Proposed model. 
Table 1. Items, factor loading, reliability, and validity.

\begin{tabular}{|c|c|c|}
\hline \multicolumn{2}{|l|}{ Factor Loadings } & Sources \\
\hline \multicolumn{3}{|l|}{ Continuance motivation } \\
\hline I have the motivation to continue sharing videos on this social media & 0.94 & \\
\hline If I could, I would like to continue sharing videos on this social media & 0.95 & Chiang and Hsiao (2015) \\
\hline The past experience motivates me to continue sharing videos on this social media & 0.94 & \\
\hline
\end{tabular}

\section{Sharing behaviour}

Reliability and validity measures: Cronbach's alpha $=0.86$, Composite reliability $=0.91, A V E=0.78$

\begin{tabular}{lll}
\hline I usually actively share my experiences with others on this social media & 0.91 & Chiang and Hsiao (2015) \\
I have contributed knowledge to other members on this social media & 0.89 & 0.85 \\
I have tried to share my videos with other members on this social media & \\
\hline
\end{tabular}

Video creation

Reliability and validity measures: Cronbach's alpha $=0.87$, Composite reliability $=0.92$, AVE $=0.79$

\begin{tabular}{lll}
\hline I can create some interesting video & 0.83 & Chiang and Hsiao (2015) \\
I am good at creating some interesting video & 0.93 & 0.91 \\
I often create some interesting video & & \\
\hline
\end{tabular}

Stickiness

Reliability and validity measures: Cronbach's alpha $=0.84$, Composite reliability $=0.90$, AVE $=0.76$

\begin{tabular}{lll}
\hline I would stay longer on this social media than on others & 0.78 & Chiang and Hsiao (2015) \\
I would stay on this social media as often as I can & 0.93 & 0.89
\end{tabular}

turned to theory. This technique is capable of expressing theoretical concepts through complex variables (constructs) to study their relationships, using a structural model. The configuration of the observable indicators and their relationships is caused by the theoretical concepts, i.e., the theoretical concept previously analyzed must be the cause of the union of the observable indicators (Benítez et al., 2020). In this case, the reflective measurement model is used because the outer weights are the correlations between the construct and the indicators. The analyses of this study have been carried out using SmartPLS 3.3.2 (Ringle et al., 2015).

Table 2. Sample information.

\begin{tabular}{lcc}
\hline Gender & $\%$ & Total 2,301 \\
Male & 43.1 & 922 \\
Female & 56.9 & 1,309 \\
\hline Age & $\%$ & Total 2,301 \\
16-25 (centennials) & 61.7 & 1419 \\
26-40 (millennials) & 38.3 & 882 \\
\hline Educational level & $\%$ & Total 2,301 \\
Basic education & 8.9 & 204 \\
Intermediate studies & 30.2 & 694 \\
Higher education & 61.0 & 1,403 \\
\hline TikTok usage frequency & $\%$ & Total 2,301 \\
Every day & 46.9 & 1,080 \\
Every 2-3 days & 13.6 & 314 \\
Every 1-4 weeks & 15.9 & 365 \\
Less than once a month & 23.6 & 542 \\
\hline TikTok usage time on a typical day & $\%$ & Total 2,301 \\
0-15 minutes & 35.0 & 806 \\
16-30 minutes & 22.1 & 508 \\
31-60 minutes & 25.3 & 17.6 \\
More than 1 hour & & 583 \\
\hline
\end{tabular}


Assessing the reliability and validity of PLS modeling (PLS-SEM) should be the first step to be taken. The first result to analyze is the relationship that each item shows with its own latent construct (see Table 1). In this case, all loadings have a higher value on their construct than on any other and exceed the value of 0.78 . Items with loadings of 0.707 or more are accepted as they reach the level of acceptable reliability (Hair et al., 2011). The next step is to assess internal consistency. For this purpose, Cronbach's alpha has traditionally been used and, more recently, composite reliability. For this study, all constructs (reflective measures) obtain a coefficient for both indices above 0.84 , as shown in Table 1 . Therefore, even in the case of demanding strict reliability, the values exceed 0.80 (Nunnally \& Bernstein, 1994). Internal consistency is also measured through the average variance extracted ( $A V E)$, in this case, in all the coefficients of each construct the AVE exceeds 0.76. A value at least equal to 0.5 is recommended. Finally, the discriminant validity in the model is recently measured through the heterotraitmonotrait ratio of correlations. If the value is less than 0.90 , discriminant validity between two reflective constructs has been established (all values of the model coefficients are below 0.72).

The Standardized Root Mean Square Residual (SRMR) was established as a goodness-of-fit measure for PLS-SEM, indicating how well a model fits the sample data. For this model, SRMR is 0.051 , suggesting a good fitting model. The results of the model also suggest that the variables explain a good amount of variance in stickiness, with $R^{2}$ value of 0.36 .

The results of the model are presented by dividing the sample between millennials and centennials.
The results (see Figures 2 and 3) show how stickiness is related to each of its causal variables in each of the segments analysed. With coefficients of 0.23 and 0.33 , for centennials and millennials respectively, the results suggest that sharing behaviour is the most important positive influence on stickiness, followed by video creation. The coefficient of the relationship between these variables is 0.21 for centennials and 0.28 for millennials. In both cases, it is a positive relationship. Finally, continuance motivation is also influencing positively on stickiness in a relevant way (with coefficient values of 0.18 and 0.13 for centennials and millennials, respectively). Consequently, all hypotheses proposed ( $\mathrm{H} 1, \mathrm{H} 2$, and $\mathrm{H} 3$ ) are not rejected in both established segments.

\section{Discussion and Conclusions}

The relationships proposed in the model have been generally accepted in the literature (Chiang \& Hsiao, 2015; Törhönen et al., 2020). However, with the model validated in this work, the authors of this study have gone beyond the existing literature in the sense that they include all the variables in the same model for the case of a social network based on videos. In addition, the differences have been analysed for the case of centennials and millennials. This study shows that the sharing behaviour variable is the variable that has the strongest relationship with stickiness. The study also examines the important impact of continuance motivation in the constant use of this platform. One of the variables included in this study was video creation. In this type of video-based social network, the perceived ability to create videos plays an important role in social network stickiness. If users

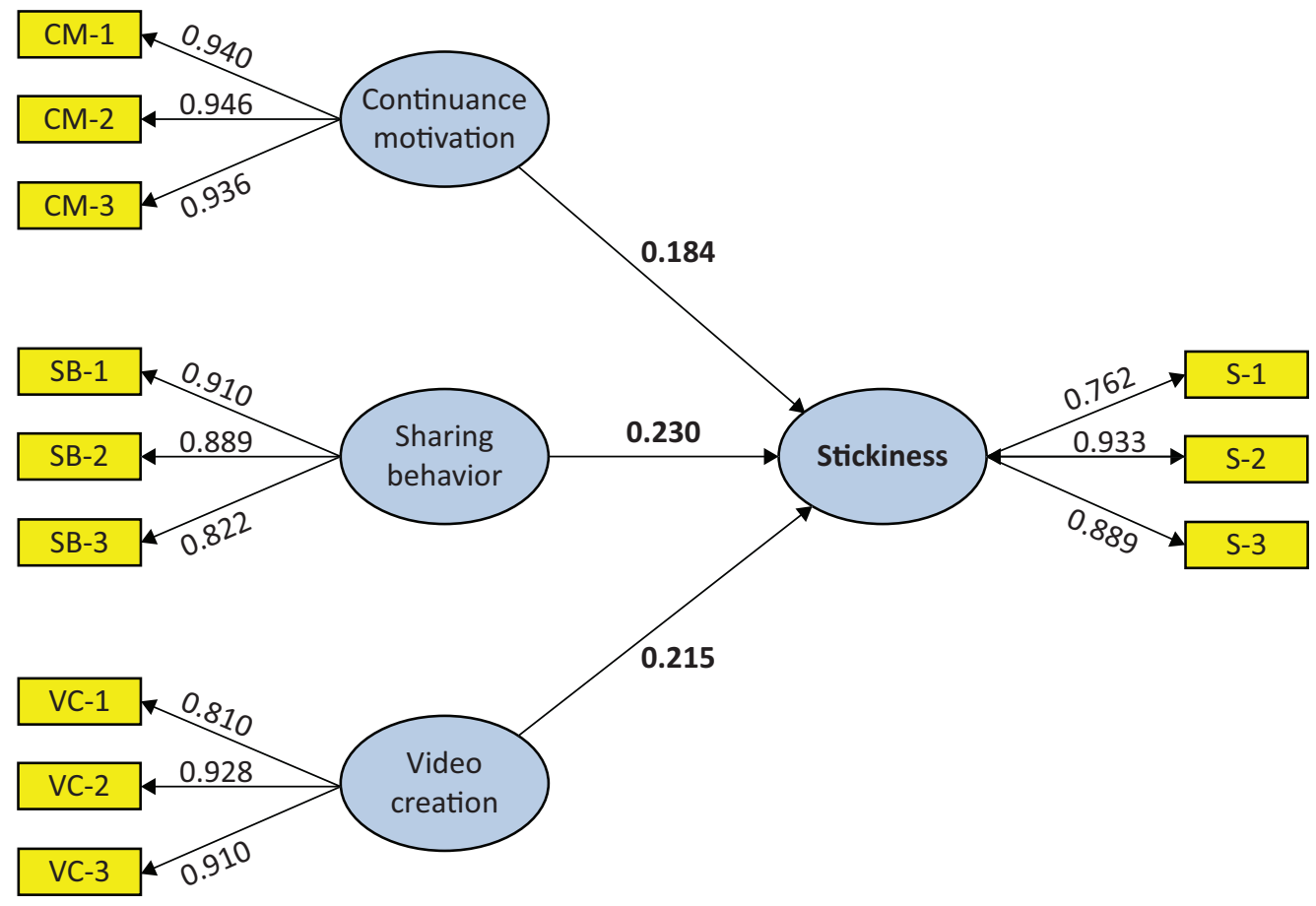

Figure 2. Model result for centennials. 


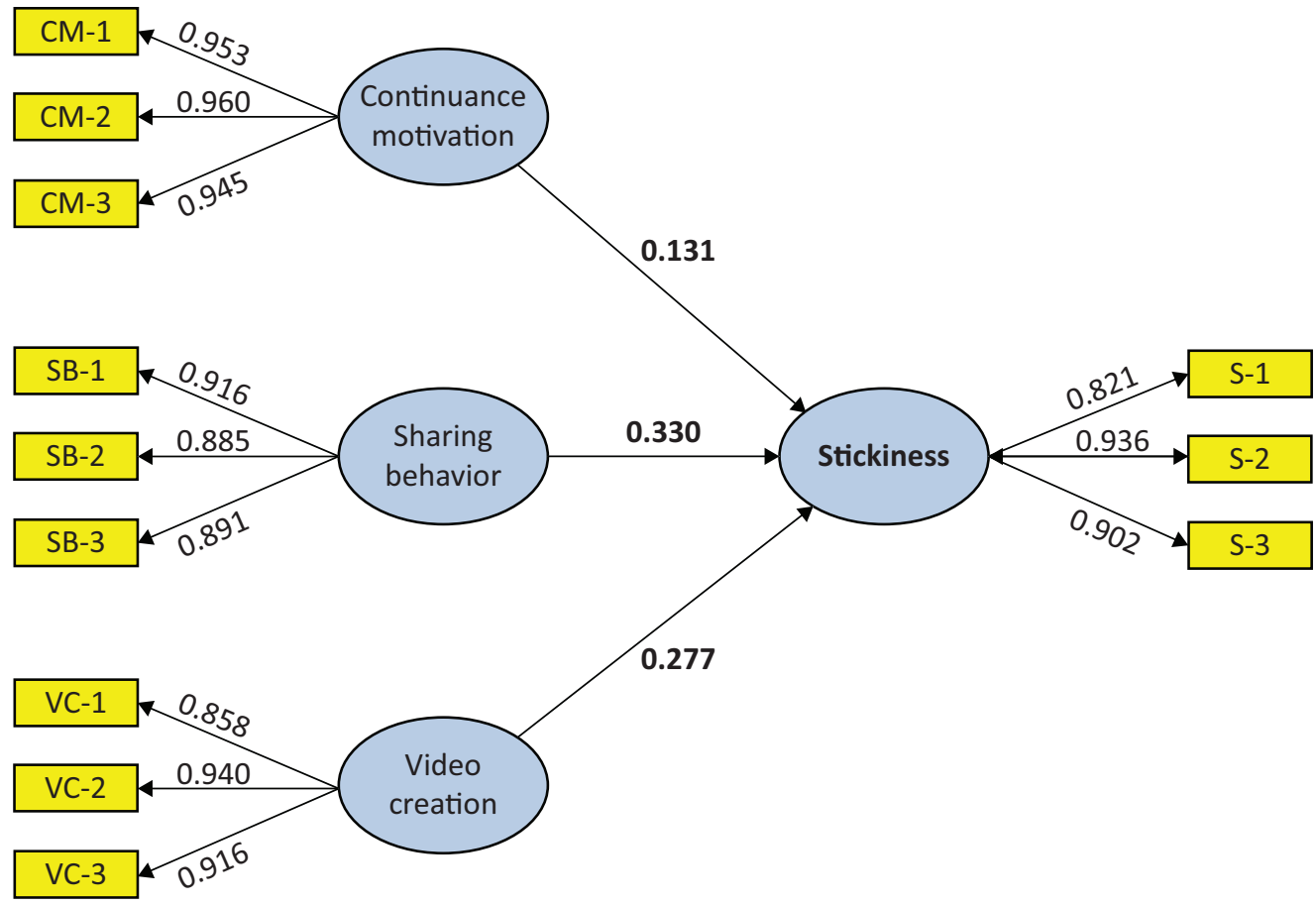

Figure 3. Model result for millennials.

feel that they have the ability to create good and valuable content on TikTok, their stickiness towards the platform is likely to be higher. Therefore, the results of this study again demonstrate the evident effect of sharing behaviour, continuance motivation, and video creation on stickiness. The findings are consistent with previous studies in various contexts (e.g., Chiang \& Hsiao, 2015; Cuesta-Valiño et al., 2020; Törhönen et al., 2020). In these studies, sharing behaviour shows a strong influence on stickiness, while continuance motivation has a weak influence. In the case of video creation perception, this variable did not obtain either a direct or indirect relevant relationship with stickiness in different social networks or digital services. Moreover, these results occur in both segments analysed: centennials and millennials. Indeed, the main differences emerge in the greater relevance of sharing behaviour for millennials than for centennials. Thus, millennials show a strong relationship between sharing behaviour and stickiness that is not comparable with the relationship in the case of centennials. The video creation variable also has a greater importance for millennials. The opposite is true for the variable that has the least influence on stickiness: Continuance motivation shows greater relevance for centennials than for millennials.

Given the importance of continuous motivation, in terms of the practical implications, these results allow us to establish that companies have the opportunity to motivate their audiences to increase adherence to the social network and, in turn, increase engagement. To do this, they could comment on and/or share fan publications to give them greater visibility. This type of action is especially useful in the case of centennials. This study provides the keys for social network developers to continue to expand into the creation of simpler interfaces, ensuring that audiences feel comfortable creating visual content. If they perceive that they are able to create content, so stickiness to the platform will grow. These types of actions are especially noteworthy for millennials. Finally, companies on TikTok should try to provide a unique experience, creating a connection to attract users to share that content with their like-minded peers. They can incentivize their followers and customers through TikTok by rewarding the most creative content of the week or month and they can reward the profiles with the most activity and engagement. Given that the industry of short and fast consumption videos is growing (Liu et al., 2019) and has a special impact on centennials and millennials, it is important that companies begin to familiarize themselves with the production of digital content based on this format, thus building a bridge with these potential audiences. These types of actions are relevant to both centennials and millennials but above all to millennials, who choose to promote particular experiences that reflect their individuality. Thus, it is important that companies understand how to identify what users are trying to express.

In short, the results of this study once again demonstrate the evident effect of sharing behaviour, continuance motivation and video creation on stickiness. The article expands our understanding of social media network stickiness-specifically on TikTok. While studies on stickiness have previously focused on platforms such as YouTube, Facebook, Twitter, and general apps or websites, this study centres on TikTok, currently one of the most important platforms and one that makes 
use of video formats. It also provides some guidelines to enhance investigation into video platforms, which are differentiated by the type of content that users upload and consume, providing an opportunity to explore the relationship between the range of variables and segments.

\section{Acknowledgments}

The authors want to thank the collaboration to the Research Group of University of Alcalá: Consumer Behaviour, Organisational, and Market Analytics.

\section{Conflict of Interests}

The authors declare no conflict of interests.

\section{References}

Balakrishnan, J., \& Griffiths, M. (2017). Social media addiction: What is the role of content in YouTube? Journal of Behavioral Addictions, 6(3), 364-377. https://doi.org/10.1556/2006.6.2017.058

Benítez, J., Henseler, J., Castillo, A., \& Schuberth, F. (2020). How to perform and report an impactful analysis using partial least squares: Guidelines for confirmatory and explanatory IS research. Information \& Management, 57(2), 103-168. https://doi.org/ 10.1016/j.im.2019.05.003

$\mathrm{Bi}, \mathrm{X} .$, \& Tang, C. (2017). Research on the motives affecting the behavior of short video's creators. IEEE Access, 8, 188415-188428. https://doi.org/10.1109/ACCESS. 2020.3028392

Boyd, D., \& Ellison, N. (2008). Social network sites: Definition, history, and scholarship. Journal of ComputerMediated Communication, 13(1), 210-230. https:// doi.org/10.1111/j.1083-6101.2007.00393.x

Camilleri, M., \& Falzon, L. (2020). Understanding motivations to use online streaming services: Integrating the technology acceptance model (TAM) and the uses and gratifications theory (UGT). Spanish Journal of Marketing - ESIC Emerald Publishing Limited, 25(2), 216-236. https://doi.org/10.1108/SJME04-2020-0074

Cao, D., Meadows, M., Wong, D., \& Xia, S. (2021). Understanding consumers' social media engagement behaviour: An examination of the moderation effect of social media context. Journal of Business Research, 122, 835-846. https://doi.org/10.1016/ j.jbusres.2020.06.025

Chen, Z., He, Q., Mao, Z., Chung, H., \& Maharjan, S. (2019). A study on the characteristics of douyin short videos and implications for edge caching. In Proceedings of the ACM Turing Celeration Conference-China (pp. 1-6). ACM.

Chiang, H., \& Hsiao, K. (2015). YouTube stickiness: The needs, personal, and environmental perspective. Internet Research, 25(1), 85-106. https://doi.org/ 10.1108/IntR-11-2013-0236
Chiu, C., Hsu, M., \& Wang, E. (2006). Understanding knowledge sharing in virtual communities: An integration of social capital and social cognitive theories. Decision Support Systems, 42(3), 1872-1888. https:// doi.org/10.1016/j.dss.2006.04.001

Cuesta-Valiño, P., Rodríguez, P. G., \& Núñez-Barriopedro, E. (2020). Perception of advertisements for healthy food on social media: Effect of attitude on consumers' response. International Journal of Environmental Research and Public Health, 17, Article 6463. https://doi.org/10.3390/ijerph17186463

Fitriani, W., Budi, A., Nizas, A., \& Munajat, Q. (2020). Reviewer's communication style in YouTube productreview videos: Does it affect channel loyalty? Heliyon, 6(9), Article e04880. https://doi.org/10.1016/ j.heliyon.2020.e04880

Hair, J. F., Ringle, C. M., \& Sarstedt, M. (2011). PLSSEM: Indeed a silver bullet. Journal of Marketing Theory and Practice, 19(2), 139-152. https://doi.org/ 10.2753/MTP1069-6679190202

Hsu, C., \& Chuan-Chuan Lin, J. (2016). Effect of perceived value and social influences on mobile app stickiness and in-app purchase intention. Technological Forecasting \& Social Change, 108, 42-53. https://doi.org/ 10.1016/j.techfore.2016.04.012

Hsu, C., \& Liao, Y. (2014). Exploring the linkages between perceived information accessibility and microblog stickiness: The moderating role of a sense of community. Information \& Management, 51, 883-844. http://dx.doi.org/10.1016/j.im.2014.08.005

Hsu, M.-H., Chang, C.-M., Lin, H.-C., \& Lin, Y.-W. (2015). Determinants of continued use of social media: The perspectives of uses and gratifications theory and perceived interactivity. Information Research, 20(2). http://informationr.net/ir/20-2/paper671.html \#.Ya9DOS2tGqQ

Hu, L., Min, Q., Han, S., \& Liu, Z. (2020). Understanding followers' stickiness to digital influencers: The effect of T psychological responses. International Journal of Information Management, 54, Article 102169. https://doi.org/10.1016/j.ijinfomgt.2020.102169

Khan, M. (2017). Social media engagement: What motivates user participation and consumption on Youtube? Computers in Human Behavior, 66, 236-247. https://doi.org/10.1016/j.chb.2016.09.024

Kim, H., Molefi, L. W., Kim, A., Woo, W., Segev, A., \& Lee, U. (2017). It's more than just sharing game play videos! Understanding user motives in mobile game social media. In G. Mark, S. Fussell, C. Lampe, M. C. Schraefel, J. P. Hourcade, C. Appert, \& D. Wigdor (Eds.), Proceedings of the $2017 \mathrm{CHI}$ Conference Extended Abstracts on Human Factors in Computing Systems (pp. 2714-2720). ACM. https://doi.org/ 10.1145/3027063.3053199

Klobas, J. E., McGill, T. J., Moghavvemi, S., \& Paramanathan, T. (2018). Compulsive YouTube usage: A comparison of use motivation and personality effects. Computers in Human Behavior, 87, 129-139. 
https://doi.org/10.1016/j.chb.2018.05.038

Konstantinos, A., Charalambos, T., \& Grouios, G. (2002). Perceived constraints on recreational sport participation: Investigating their relationship with intrinsic motivation, extrinsic motivation and amotivation. Journal of Leisure research, 34(3), 233-252. https:// doi.org/10.1080/00222216.2002.11949970

Koster, A., Matt, C., \& Hess, T. (2020). Do all roads lead to Rome? Exploring the relationship between social referrals, referral propensity, and stickiness to video-on-demand websites. Business \& Information Systems Engineering, 63, 349-366. https://doi.org/ 10.1007/s12599-020-00660-1

Kwane, J., Adams, S., Kofi, I., Ebo, P., \& Odei, S. (2020). Digital identity management on social media: Exploring the factors that influence personal information disclosure on social media. Sustainability, 12(23), Article 9994. https://doi.org/10.3390/su12239994

Lee, C., \& Ma, L. (2011). News sharing in social media: The effect of gratifications and prior experience. Computers in Human Behavior, 28(2), 331-339. https:// doi.org/10.1016/j.chb.2011.10.002

Lee, E., Lee, J., Moon, J., \& Sung, Y. (2015). Pictures speak louder than words: Motivations for using Instagram. Cyberpsychology, Behavior and Social Networking, 18(9), 552-556. https://doi.org/10.1089/cyber.2015. 0157

Lee, M., \& Quillian, E. (2019). Motivations for sharing marketer-generated content on social media: A comparison between American and Korean college students. Journal of Consumer Marketing, 36(1), 206-217. https://doi.org/10.1108/JCM-07-20161875

Lien, C., Cao, Y., \& Zhou, X. (2017). Service quality, satisfaction, stickiness, and usage intentions: An exploratory evaluation in the context of WeChat services. Computers in Human Behaviour, 68, 403-410. https://doi.org/10.1016/j.chb.2016.11.061

Lim, B., Lu, D., Chen, T., \& Kan, M. (2015). \#mytweet via Instagram: Exploring user behaviour across multiple social networks. ACM International Conference on Advances in Social Networks Analysis and Mining, 2015, 113-120. https://doi.org/10.1145/ 2808797.2808820

Liu, G., Gao, P., Li, Y., \& Zhang, Z. (2019). Research on the influence of social media short video marketing on consumer brand attitude. In X. Xiao, T. Hauer, \& S. A. R. Khan (Eds.), Proceedings of the 2019 5th International Conference on Social Science and Higher Education (ICSSHE 2019) (pp. 433-438). Atlantis Press. https://doi.org/10.2991/icsshe-19.2019.192

Lortie, C. L., \& Guitton, M. J. (2013). Internet addiction assessment tools: Dimensional structure and methodological status. Addiction, 108(7), 1207-1216. https://doi.org/10.1111/add.12202

Lu, H., \& Lee, M. (2010). Demographic differences and the antecedents of blog stickiness. Online Information Review, 34(1), 21-38. https://doi.org/10.1108/
14684521011024100

Ma, W., \& Chan, A. (2014). Knowledge sharing and social media: Altruism, perceived online attachment motivation, and perceived online relationship commitment. Computers in Human Behaviour, 39, 51-58. https://doi.org/10.1016/j.chb.2014.06.015

Marchand, D. (2000). Mastering information management. Financial Times Management.

Nunnally, J. C., \& Bernstein, I. H. (1994). The assessment of reliability. Psychometric Theory, 3, 248-292.

Page, K., Flanagin, A. J., \& Metzger, M. J. (2014). Social media self-efficacy and information evaluation online. Computers in Human Behaviour, 39, 254-262. https://doi.org/10.1016/j.chb.2014.07.020

Pappas, I., Papavlasopoulou, S., Mikalef, P., \& Giannajos, M. (2020). Identifying the combinations of motivations and emotions for creating satisfied users in SNSs: An fsQCA approach. International Journal of Information Management, 53, Article 102128. https://doi.org/10.1016/j.ijinfomgt.2020.102128

Park, G., Chen, F., \& Cheng, L. (2021). A study on the millennials usage behavior of social network services: Effects of motivation, density, and centrality on continuous intention to use. Sustainability, 13(5), Article 2680. https://doi.org/10.3390/su13052680

Ringle, C. M., Wende, S., \& Becker, J. M. (2015). SmartPLS 3 [Computer software]. SmartPLS GmbH.

Sydow, L. (2020, December 9). 2020: What happened in mobile and how to succeed in 2021. App Annie. https://www.appannie.com/en/insights/marketdata/2020-mobile-recap-how-to-succeed-in-2021

Törhönen, M., Sjöblon, M., Hassan, L., \& Hamari, J. (2020). Fame and fortune, or just fun: A study on why people create content on video platforms. Internet Research, 30(1), 165-190. https://doi.org/10.1108/ INTR-06-2018-0270

Vermeulen, J., Vandebosch, H., \& Heirman, W. (2018). Smiling, \#venting, or both? Adolescents' social sharing of emotions on social media. Computers in Human Behavior, 84, 211-219. https://doi.org/ 10.1016/J.CHB.2018.02.022

Wang, W., Wang, Y., \& Liu, E. (2016). The stickiness intention of group-buying websites: The integration of the commitment-trust theory and e-commerce success model. Information \& Management, 53(5), 625-642. https://doi.org/10.1016/j.im.2016.01.006

Weeks, B., Ardevol-Abreu, A., \& Gil de Zúñiga, H. (2017). Online influence? Social media use, opinion leadership, and political persuasion. International Journal of Public Opinion Research, 29(2), 214-239. https:// doi.org/10.1093/ijpor/edv050

Wu, J., Lien, C., Mohiudding, M., Chien, S., \& Yang, X. (2016). The effects of smartphone users' core selfevaluations and stickiness on intentions to download free social media apps. Journal of Decision Systems, 25(3), 263-272. https://doi.org/10.1080/12460125. 2016.1187549

Wu, J., Wang, S., \& Tsai, H. (2010). Falling in love 
with online games: The uses and gratifications perspective. Computers in Human Behavior, 26(6), 1862-1871. https://doi.org/10.1016/j.chb.2010.07. 033

Xu, F., Qi, Y., \& Li, X. (2018). What affects the user stickiness of the mainstream media websites in China? Electronic Commerce Research and Applications, 29, 124-132. https://doi.org/10.1016/j.elerap. 2018.05.001

Yang, H., \& Lin, C. (2014). Why do people stick to Facebook website? A value theory-based view. Information Technology \& People, 27(1), 21-37. https://doi. org/10.1108/ITP-11-2012-0130

Yen, C. (2016). How to unite the power of the masses? Exploring collective stickiness intention in social network sites from the perspective of knowledge sharing. Behaviour \& Information Technology, 35(2), 118-133. https://doi.org/10.1080/0144929X. 2015.1105297

Zhang, M., Guo, L., Hu, M., \& Liu, W. (2017). Influence of customer engagement with company social networks on stickiness: Mediating effect of customer value creation. International Journal of Information Management, 37(3), 229-240. https://doi.org/ 10.1016/j.ijinfomgt.2016.04.010

Zott, C., Amit, R., \& Donley, J. (2000). Strategies for value creation in e-commerce: Best practice in Europe. European Management Journal, 18(5), 463-475. https://doi.org/10.1016/S0263-2373(00)00036-0

\section{About the Authors}

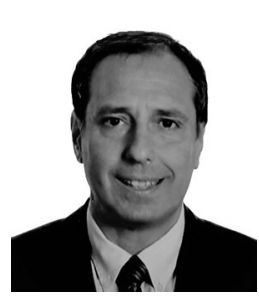

Pedro Cuesta-Valiño has a PhD in business and is a professor of marketing at Universidad de Alcalá (Spain). His priority line of research is consumer and organizational behaviour. He is the author of more than 80 research papers that have been published in several academic journals. He is also the executive editor of International Journal of Internet Marketing and Advertising, and he is part of the editorial board of International Journal of Consumer Studies, Spanish Journal of Marketing, and Revista Portuguesa de Estudos Regionais.

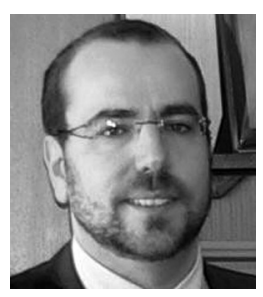

Pablo Gutiérrez-Rodríguez has a PhD in marketing and he is a professor and researcher at Universidad de León. His research has been published in several academic journals, specialized in management (Corporate Social Responsibility and Environmental Management, Journal Retailing and Consumer Services, or Economic Research) and in numerous chapters published in the most relevant international editorials in economics. He is a regular lecturer at numerous national and international marketing conferences.

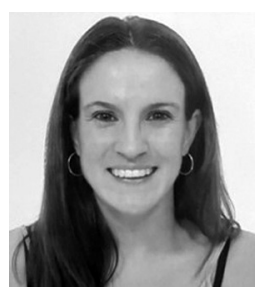

Patricia Durán-Álamo has a double degree in journalism and audiovisual communication from the Rey Juan Carlos University of Madrid and specialized in communication and corporate identity from the International University of La Rioja. She is a lecturer in the marketing and market research area of the Universidad de Alcalá. As a professional, she manages the communication of companies through offline communication strategies (press releases, PR, among others) and online (social networks, chatbots, SEO, SEM, etc.) of technology-based companies. 